DE DE GRUYTER OPEN
Research Article

(C) 2018 Mehtab et.al. This is an open access article licensed under the Creative Commons Attribution-NonCommercial-NoDerivs License (http://creativecommons.org/licenses/by-nc-nd/3.0/).

\section{Virtual Leadership: A Review Paper}

\author{
Khurram Mehtab \\ Assistant Professor, Department of Management Science, \\ University of Haripur, Pakistan \\ Amjad ur Rehman \\ PhD Scholar, Riphah School of Leadership, \\ Riphah International University, Islamabad, Pakistan \\ Saira Ishfaq \\ PhD Scholar, Faculty of Management Sciences, \\ International Islamic University, Islamabad, Pakistan \\ Raja Ahmed Jamil \\ PhD Scholar, Riphah School of Leadership, \\ Riphah International University, Islamabad, Pakistan
}

Corresponding Author

Doi: 10.2478/mjss-2018-0089

\title{
Abstract
}

In today's competitive business environment, virtual work settings present a growing challenge for rapid solutions of organization's complex problems. This enables an organization to pool talent and expert employees by eradicating the time and space barriers. In accordance, companies are profoundly investigating on virtual teams' performance enhancement. Virtual work settings revolutionize workplace by providing high level of responsiveness and flexibility. Virtual work setting has also many issues and challenges which must be addressed in order to enhance the team's performance. Hence one of the major challenge of modern work setting is virtual leadership. This review paper presents an introduction to virtual leaderships, advantages of virtual work environment, challenges and recommendations for virtual leaders to enhance the performance of virtual teams. This article also offers review of earlier published researches and reports the findings on virtual team leadership in a struggle to the present the current state of work on this topic.

Keywords: Virtual Leadership, Virtual Teams, Challenges of Virtual Teams, Advantages of Virtual Work Settings, Recommendations for Virtual Teams, Review paper

\section{Introduction}

\subsection{Background}

The working environment of organizations has changed now. Presently, the business activities have become more global and competitive as compared to the past. All this happened due to faster pace of advancement in information and communication technologies, which rendered the jobs more dynamic and multidimensional. In order to respond to such changes, organizational structures, systems and processes have improved and become more adaptive and flexible. Due to such advancements of technology the trend towards virtual teams as unit of an organization has increased. Now a days, many organizations have shifted from conventional team work to virtual team work. 
The concept of virtual working style is not new. Through communication technology this type of working has been practiced since many years and extensive literature is available on this topic at the moment. However, the concept of virtual work setting is remained unsatisfactory and considered as second class (Something to do when one can't travel). Due to faster globalization and to welcome Generation $\mathrm{Y}$ in corporate world the concern for virtual environment for better quality of work become more critical.

Due to advancement in technology, organizations are heavily relying on virtual teams for accomplishment of organizational goals and objectives. It is a greater challenge to lead such teams as the prevailing literature on leadership of virtual teams does not translate directly into leadership context. Almost every organization of current era is involved to work in virtual environment settings either fully or partially, especially the multinational companies are much dependent on it. It is not difficult for any company to set up the virtual working environment these days because of easy availability of infrastructure and software. However, the leadership is a really difficult job to perform in such environment at all the time. This paper explores the Virtual Leadership perspective by exploring the extant literature on this topic. It is believed that this review paper will help virtual leaders to understand the virtual work settings in a better way and will ultimately lead to an increase the team's performance.

\subsection{Definition}

According to Zigurs (2003), virtual teams are collection of individuals, dispersed from each other geographically or organizationally but connected by information technology to accomplish assigned goals. Although, face-to-face teams are considered to be in complete contrast as compared to virtual teams, few researchers defined the degree of virtuality on different scale (Griffith, Sawyer, \& Neale, 2003). The level of virtuality is either low or high, depending upon the mode of communication is used between the members of virtual teams. If the members are exchanging the information in real time, then the level of virtuality is low. In case if there is a lag or interruption in exchange of information, it will result in higher level of virtuality.

The general perception of people about virtual working is something that does not exist in reality and according to many managers' point of view, personal contact can only associate face-to -face. The extensive literature and books on virtual work setting is helpless to overcome the apprehension of working virtually as it has still remained in people head's something that unreal and have limited benefit due to its strong association with technology. It is very interesting to share that the word virtual appeared in late 14th century with meaning as "influencing by physical virtues or capabilities".

\subsection{Concept of Leadership in Virtual Environment}

The one of the major challenge of virtual teams is leadership. It is very difficult for a team leader to control directly every team member's activity due to different geographical location. Consequently, leader considers the delegation principle of management by shifting managerial functions down the hierarchy to the other team members. But the acceptance and fulfillment of these managerial functions depend on motivational level and identification of goals by team members, which is very difficult again to achieve in virtual environment. The virtual leader can't physically observe the members and should be creative to observe the expectations virtually. Virtual team leader can't assume that members are ready to start virtual meetings. Virtual leader must have a sense to understand that an electronic silence means acquiescence rather than inattention.

There are three basic roles of a virtual leader. First, a liaison between team's members to interpret events and overall environment. Second, as a direction setter to ensure all actions having specified purpose and those actions are in line with team's overall goals and objectives. Third, leader role should be an operational coordinator for the identification of right resources and development of tactics to solve the problems. Leader must motivate and empower employees to inspire greater efforts for goal achievement and minimize the losses of process. These rules are not much different from traditional rules but must be carried out in virtual team settings with limited 
communication (Zaccaro \& Bader, 2003).

A virtual team is mare a collection of individuals at the time of its creation. The role of leader from the inception is to create coherence and integration among these individuals to achieve the targeted goals. For this purpose, there must be required a team orientation including motivational factors like endorsing a mutual goal setting, creating and shaping positive perceptions. It must present the bond to tie members with each other as well as with team's mission. After the creation of this environment the two major roles of leadership are team development and performance management (Hunsaker \& Hunsaker, 2008).

All types of leaders are involved in problem solving of team members. They are trying to articulate the vision of team, communicating that vision and setting plan execution to accomplish the tasks. Leaders are responsible for selecting and motivating right members, establishing right norms, inspiring social events, trust building, goals setting, preparing team to cope with all situations and developing internal communications. Successful leaders of virtual teams are involved in innovative problem solving.

Most of the time of virtual leader is spent in mentoring team members, enforcing standards and rewarding team members. It is very difficult to do that all without physical presence. The collocated teams can observe the members physically if team is getting inactive, when team members need a social event to rebuild momentum or when team needs direction or focus and when teams needs resources. It is leader's responsibility to ensure that knowledge of each participating member has been fully utilized.

The major reason of unsatisfactory status of virtual working is due to its leadership aspect that has been underestimated and overlooked. In view of some researchers, virtual teams are independent and have lack of a formal leadership (Balthazard, Waldman, Howell, \& Atwater, 2004). In Zigurs (2003) point of view, only the assigned leader is not sufficient but leadership behavior is required to move forward.

The Virtual leadership is intervened using information technology by focusing the performance and relationship of members to enhance the output; it is highly dependent on the information availability and communication permanence (Avolio, Kahai, \& Dodge, 2001). Moreover, there are some collaborative features of technology that can be substitute for traditional style of leadership (Avolio \& Kahai, 2003).

According to Powell and Piccoli (2004) Virtual Leadership has several phases. First of all, it must be ensured that there is a right technology efficient for virtual working, in nineties the major focus of literature was on getting right processes and right teams in order to confirm effective virtual working. This scenario of thinking is progressively developed and led to what call "recipe book" about virtual work setting. In last few years the most literature published on the topic of trust and performance management of virtual world. The focus on virtual leadership unlike virtual team management is very limited.

\section{Literature Review}

Since the mid of 1970, team based work activities have increased and become dominant organizational form, used to achieve creativity, high performance and intrinsic motivation for employees. The well-known companies like Disney, Kodak and Xerox use such form of work settings and have become well entrenched organizations. The popularity of inter-organizational alliances has increased meanwhile and globalization accelerated the firms to coordinate activities outside the organizational boundaries (Townsend et al., 1998). Moreover, the services related businesses have expanded around the globe due to the advent of information technology. These factors inspired the organizations to coordinate across the physical boundaries, time zones and organizational context. On the basis of such demands, the face to face conventional teams have started converting into virtual teams. However, Jarvenpaa (1998) has noted some factors which may influence the negative characteristics among the virtual team members; these factors are divers' culture, distance, different time zones, globally scattered team members and their heavy dependence on computer and information technology. Virtual teams face a lot of challenges including trust, communication and team co-ordination (Jarvenpaa, 1998; Kitchen \& McDougall, 
1999; Lipnack \& Stamps, 2000; Robey, Koo, \& Power, 2000; Warkentin, Sayeed, \& Hightower, 1999). Few disadvantages have been stated by Cascio (2000) that virtual teams are less physical and lack of social interaction, lack of trust, issues concerned with predictability and reliability. Gould (1997) has stated some unsuspected danger and difficulties which are, lack of individual recognition and project visibility, obstacles in technology and lack of enthusiasm.

According to Bell and Kozlowski (2002) leadership has two primary functions in context of virtual team that are team development and performance management. The leaders of virtual teams need to distribute functions facets to the team and should make the team as a self-managed team. Team members required committing and consistency with the team and this must be conducted by outstanding leadership.

Hamilton and Scandura (2003) investigate the concept of e-mentoring in context of digital world as it is necessary for e-leadership to identify its potential challenges. The authors also identified the barriers to e-marketing such as organizational, individual, interpersonal and changing nature of the work. It was concluded that e-mentoring is an important concept which extent the flexibility and use as compare to the conventional models across the time and space.

Avolio and Kahai (2003) explain the effect of technology on leadership by exploring the impact of e-leadership on leaders, team's followers and organizations. The author elaborated further that e-leadership is not only the extension of traditional leadership but a changed way which leaders and followers have to follow within and outside the boundaries of organization. They also clarified that it may happen that there are some common rules between virtual and traditional leadership.

According to Zaccaro and Bader (2003) organizational leaders are facing two type of challenges, one is increasing global dispersion of customers, suppliers and stakeholders and the second is exponential explosion of information and communication technology which lead to lead to frequent daily interactions with colleges, subordinate and bosses dispersed physically. In response to these changes, the scientists of organizations stated to talk about e-leadership to conduct the leadership process by using electronic channels. The authors have assumed that with this pace of development in information technology the organizational growth and global reach it is expected that in near future the e-leadership will be a routine matter rather than an exception what we think about constitutional organizational leadership.

Banerjee and Chau (2004) investigate the concept of e-leadership in context of e-government. According to them main purpose of e-government in a country is to provide information and services by utilizing the information and communication technology. The ultimate objectives being desired by this system implementation is to give access to government organization and maintain the transparency. Authors used a frame work for analyzing the e-government capability in different developing countries. The study results showed that governments offer different services level and different level of quality of services across the world. The level of such services shows the government capability for e-leadership of the countries.

Gurr (2004) argued that e-leadership is a new concept with many uncertainties because there is a difference in leading a traditional organization and the one with technology medicated environment and he said that there must be an appropriate social environment and the e-leader must be able to convey skills through technology.

Howell, Neufeld, and Avolio (2005) noticed that certain changes in work such as complexity, size, organizational structure and arrangement of work compel the leader to responsible and manage the followers who are at distance. The studies revealed many hypothesis, it was tried to forecast the performance of business unit manager. The results showed that performance was rightly predicted by transformational leadership and contingent rewards are not related with performance. So physical distance among leader and their followers has negatively moderated the relationship of transformational leadership and business unit performance and positively moderated relationship among contingent reward leadership and performance.

Brake (2006) said that there are two problems that e-leaders can most probably face that are isolation and confusion. He suggested what e- leader should do to avoid these problems. Bake provided a guide line for e-leaders that includes implementing culture information, building predictability, precise communication, person centric. The author also provides opportunity for conventional leaders to re-equip themselves for virtual leadership. 
Watson (2007) examined distributed working environment by focusing the leader behavior and leadership behavior impact on subordinate's commitment and satisfaction. As the distance is increasing between workers it is being explored that is the behavior of leadership has any effect on the distributed work environment and how it affects the work results. There were some questions raised by the author included the behaviors of necessary management such as consideration and starting structure, leadership type that has the most post effect on worker perception, the importance of face to face meeting between manager and employee. According to the author there are high levels of satisfaction in collocated worker with management than the remote ones. There is a great difference between physical and virtual employee as the employee working near have greater level of carrier advancement than the one's working at long distance from each other.

Malhotra, Majchrzak and Rosen (2007) conducted a study that included surveys, interviews and observational information and showed that practice of e-leadership include the capability to maintain and built trust through information and communication technology to manage the cycle of virtual work, manage the progress of teams by using technologies to expand the visibility of members inside and outside the company and to make sure that team members get benefited from the team.

Greenberg, Greenberg and Antonucci (2007) have examined trust in a virtual team environment and said that its can only be built over the course of time due to the past trust worthy behavior. It is difficult to generate trust in virtual teams as there is no physical contact on past record of the individual. Study revealed that trust can be built in a virtual team very rapidly but that trust can be short lined or feeble. Green berg said three components can help build trust are ability, benevolence and integrity. The author has proposed how e-leadership can build and maintain trust through entire life of project.

Potential benefits and flexibility is being offered by the virtual teams work settings but there are also challenges related to leadership of such environment(Hunsaker and Hunsaker, 2008). Some of the challenges that virtual teams have to face have been mentioned by Gibson and Cohen (2006) are technological faults, communication mishaps, internal conflicts, inept work process and challenges in supporting the systems

Shriberg (2009) has noted that initially virtual team leadership was thought to be important only for large business but presently it has become necessary for almost every business which strive to prosper. For virtual teams and team work management the company does not required making an office in foreign countries and in different cities. However, the virtual leaders required to build human and technical support and systems to make able organization to sustain in competitive environment. Virtual leadership is a great task which shows the influence of a leader because it's a complicated jot to lead people around the world having different time zones, languages and culture.

Avolio, Walumbwa, and Weber (2009) said that virtually leading is not only involves people of one's own company but sometime also need to involves people form rival companies. Challenges occur more often across various time zones when there is widespread competition for target achieving, failure of local communication systems or basic services requirement for making software and hardware compatible does not exist together or demands of urgent attention to fulfill priorities. There are some questions concerning e-leadership as identified by the author are: How is the leadership style which has a great effect on follower's progress and motivation is dependent on the nature of technology? How trust formation is influenced by e-leadership? Is the nature of technology an important factored in building trust in virtual teams? How leadership is affected by the nature of task and its difficulties? How the leadership affects team performance in virtual environment?

Darleen (2009) stated that as the virtual teams are become more predominant, organizations should take a close look to ensure the success of such teams. The leadership of virtual team's required to manage from distance and consequently face unique challenges and issues.

An experiment was carried out by Purvanovaa and Bono (2009) of transformational leadership in virtual teams' context and conventional face to face teams. There were thirty nice leaders to lead both teams. Leader rank was different between both because in virtual team they turned out to be more effective leaders as they had increased their transformational leadership style. Analysis at team level also proved that effect of transformational leadership was making stronger in virtual 
team than face to face team. It is concluded by the author that transformational leadership has great impact on virtual team and leaders with transformational style of leadership in virtual team can achieve higher performance level.

Colfax, Santos and Diego (2009) argued about the necessity of virtual team in local and global businesses especially when the employees are reluctant to move to other places. Before the inception of virtual team concept when a manager or any employee with technical skills was needed in some foreign place other than home town they were urgently moved. But in the new era the need of global operations has been changed; now there is no need to move the people from one place to another. However, it is very essential to build up virtual work environment and take advantages of the technology which is in our approach. There is also a need for making a new example of virtual organizational management but it requires proper training of workers, reliability of working environment technology, acceptance of one's own task with enthusiasm and communication among member of a team. These are the basis for the formation of e-leadership spread across the globe to manage virtual team and their operations.

The challenge of e-leadership in health care organization have also been studied by Holland, Malvey, and Fottler (2009). The health care organizations have to face many challenges as they move and spread out into global market. There are lot of issues concerning leadership and the leading individuals those are usually geographically scattered. There are three new ways to improving the health care organizations that are medical tourism, obtaining resources from foreign counties and tele robotic. Leaders are required by these models to lead the team members virtually. The authors have provided a guideline for the global health care organizations so they can be led and inspired and are able to face challenges such as language issues, cultural diversity and technological problems.

Kerfoot (2010) has described virtual leadership as like leading of an organization which is not physical, in short, it is the management of the work that has been distributed among the members who communicate and contact with each other for their work through electronic media. The virtual leaders must have the ability to inspire people from long distances and develop self-managing qualities in employees. The virtual leaders must know how to cross barriers of culture, time and distances about new changes in places where direct supervision and control is impossible. To maintain the high-performance of group across the boundaries new abilities are required. It is concluded by the author that virtual leaders must be dependent on coaching and not supervision.

Miller, Aqeel-Alzrooni and Campbell (2010) have presented learning from an interdisciplinary co-operation undertaking in the virtual environment between four different teams of university. The purpose of this activity was to make the students able to learn experimentally the use of a dynamic social network analysis tools for various projects. Inter and multi-disciplinary co-operation challenged the teams to quickly and clearly communicate and show the values of key principles, methods and work practices while negotiating a variety of difficulties, cultural knowledge, skills and abilities. The authors presented a frame work of future co-operation in such working environment.

Email networks and technology has been discussed by Bishop, Riopelle, Gluesing, Danowski and Eaton (2010) to support the virtual teams working globally. The authors accepted that in history management of employees that are located at different locations has trusted mostly on e-mail to track issues, to manage performance and distribute the workload. But these methods are not applicable for high data volume because of insufficient information. As a consequence, the understanding of virtual team members of a distant manager is distorted by insufficient information as compare to the information they usually obtain by being in close contact to employees. To make the virtual manager understand better the authors have proposed a set of tool called Digital Diffusion Dashboard which provide analytical matrix for better understanding of network through which he is connected with virtual team. These tools present analytics relevant to volume, time, interaction of employees on regular basis, influence of culture on the employee, team collaboration, interaction, emotion and collaboration. Moreover, the tools also held in adoption of new global prospects and change of staff as it shortens the time of change for both existing and incoming employees. These measurements have a strong influence specifically in virtual teams where there is need to assist and to fill the gap of location and performance.

Collaborative networks innovation has been studied by Luther and Bruckman (2010). The 
authors investigate that how they utilized virtual team concept in collaborative network and can be creative. The author tried to studies the non-business activities. They study the online communication of flash animation by armature that co-operated with one another on internet and created animated movies and games. There are almost 900 games on new grounds.com which are found to be very successful projects attracting thousands of internet audience to download them. They studied the model for explicit factors including attributes of e-leader and virtual structure of organizational. The research was based on the social dynamics with collapse specifically to test the role of e-leadership.

\section{Challenges for Virtual Leadership}

The most crucial challenge for virtual leader is to integrate his/her personal life with virtual team demands. As the members of virtual teams are spread in different time zones, this requires different plans for call or conferences. Moreover, the most of work of virtual team is to be done at home, therefore, it can be problematic to create a balance between work and family matters.

The virtual teams have expanded in different geographical zones where different cultures prevail, different rules/regulations exist and different business processes are applied. This type of diversity creates problems and complexities for virtual team leaders. Whenever the virtual team is expanded across cities, countries or continents virtual team leader is required to consider different methods of communication and strategies.

In rare cases, it happened that the virtual teams are equipped with all technologies required to perform from its inception. In fact, leader imparts an attitude to work together in virtual settings and let find out the tools required for job performance. Often the team members complain about the unavailability of such tools to enhance the performance and blame the leaders that they have not provided the latest technology/tools to perform.

With advancement of information technology and change in the needs of virtual teams, leaders allow to use different types of tools depending on the availability in different regions. It's again the leader's responsibility to monitor closely the tools and latest technologies and change over period of time to be more competitive. Virtual team technologies keep evolving over time and there is always a need to change the hardware and software to remain competitive.

\section{Advantages of Working in Virtual Environment Settings}

In traditional environment where work is being done through face to face meetings, the team members wait for face to face interaction to perform brainstorming and to produce innovative ideas. However, in virtual environment setting, leader communicate on synchronous or asynchronous collaboration where interaction is not bounded by time and place.

Virtual team leader uses asynchronous methods for idea generation and evaluation. Through asynchronously facility in virtual team member can pick and select the idea when he/she wants to make contribution. This is very flexible for team members who are from diverse backgrounds and having different pace and rhythm for idea generation and understanding others' ideas. Through asynchronous methods, member with different languages are capable to share thoughts in nonnative language as compared to synchronous method where fast pace of work may be required.

The conventional leaders monitor the team progress by observing them physically but the virtual leaders do the same by monitoring what is not bounded by space. Furthermore, virtual leaders use asynchronous and synchronous patterns of communication to determine team member's participation and can determine easily which member requires more support for further involvement. Asynchronous refers to electronic documents and knowledge repository whereas synchronous refers to virtual meetings and messages e.g. instant messages.

The leaders of virtual teams also use the communication technology for training and coaching for team members. This can be done in number of ways. Team leaders also track the knowledge repository regularly to monitor the members' participation and email to the members those are not participating in team activities. This is a best way to evaluate the team's member performance. Repository date log tells the leaders that that is using and how much often accessing the team 
repository. In virtual settings team leader is also assisted by a facilitator who keeps the track of usage and report to leader in case of problem. This make enable for leader to check "coasting" and social loafing when a member is fail follow work protocol or does not meet deadlines. This way also helps virtual leaders to investigate the problems in less time and threatening underperformers. Virtual leaders also attentively observer progress by using information technology team support as well as for processes.

\section{Recommendations for Virtual Leaders}

- Virtual leaders must provide the required training on participation to each member and should not assumed that best practice of traditional work will seamlessly be transferred in virtual environment.

- The coordination barriers that are associated with virtual work settings must be overcome by the leaders across different cultures, time zones and languages. Trust and cohesion must be created among team members so that they must identify the common goals and objectives.

- Leaders should provide such virtual settings in which tasks and relational roles can be assigned and monitored by the authorized/concerned members.

- Leaders must establish some sort of communication standards for internal communication between members so that the misinterpretation should be avoided.

- Leaders should select and approve appropriate tools to work and to communicate with each other, however there must be flexibility that user can select and adapt according to their needs.

- Virtual leader must arrange different ceremonies to reward the members such as gifts, cash prize or certificate of appreciation. Leader should also practice to give members a gold star for best performance. In this way members recognize the importance of their work and will perform best in future.

- The virtual leader should develop an expert's directory in the beginning. This directory should consist of member's photo, his or her previous experience, trainings, assignments and professional affiliations.

- In virtual settings environment a skills matrix should be placed at visible location, accessed by every team member to see that what expertise each member brought in team. This type of expertise directory or skills matrix is best to understand team diversity and to build competency based trust.

- Finally, the effective leadership should enhance team's experience of each member by confirming that every member has equal opportunity to learn, contribute and grow so that he/she should feel an important part of team.

\section{Future Directions}

Substantial efforts have been made to understand the virtual environment settings, but still many concerns and challenges related with efficient teamwork in these environment settings remained left. A considerable part of literature in this article has been reviewed to understand the virtual teams and its leadership but many new perspectives related to virtual leadership are begin to emerge. The major objectives of this article were to condense the available literature related to leadership of virtual team and make some recommendations for leaders and practitioners for the improvement in the leadership of virtual teams. This article reviewed general principles regarding the management and leadership of virtual environment setting; however, there is a need to studies the virtual environment settings management and leadership more specifically.

An area for future research can be the investigation on the practice of political strategies to boost up the virtual team members for better performance. However, this must be done within ethical rules boundaries and moral responsibility. In virtual work environment the vital challenge for the team leader is coordination between the team members from diverse culture and different 
geographical area. There is a need for more research on this issue that how a successful manager can make balance for better coordination between the members belong to different geographical zones and culture.

There is a need of ethical leadership for successful management of virtual teams. Further research is required to conduct for ethical virtual leadership on its impact on team members for successful management of virtual teams.

In virtual environment setting as we have discussed that the leader can monitor the team's member performance by examining their repository files without informing them. This method of evaluation leads to an ethical question with respect to privacy and trust. A research is required to be conducted to determine that such type of methods is ethical for information collection or there is a need to get member consent before accessing such repositories. If these methods are not ethical way to measure the performance of teams, then there is a need to find out the ethical methods for measuring performance through research in virtual environment.

Leadership style has a significant impact on the performance of convention work environment. As our concern is with virtual leadership so there must be a research work with respect to the impact of different leadership style on the performance of virtual teams.

Trust is considered as a fundamental element for team management and motivation. However, in virtual work settings the relationship and trust is restricted by the technology. In this case trust becomes significant challenge for virtual leaders. Establishing trust in virtual environment is very much important for team's leaders in this scenario. There is a need to study that how virtual trust can be established in virtual settings environment context.

Additional research is required to check whether the recommendation given in this review for team leaders and practitioners apply in field settings by examining the virtual teams working. Further research is needed to explore which types of trainings are required to enhance the member performance, team cohesion and coordination.

Finally, it is expected that work on virtual leadership and its different aspects will continue and it must be continued because the roles and responsibilities of virtual leaders are changed with reference to change in technology. There is always a need to respond the revolutionary working environment of virtual teams. Similarly, it is also expected that the scholar must be focused on the development of theory of virtual teams setting and the theories applied to convention work settings must be amended by the scholars to be redefined for virtual work settings.

\section{Conclusion}

This review article provides literature review that can be used for further research on virtual leadership and how virtual leadership is different from traditional leadership. With the advancement in technology as we move further towards the virtual organizations there is a need to recognize the roles and responsibilities of leaders in this work environment. The virtual work setting has improved the business organization's capability to produce the products and services and their distribution. It also increases the job satisfaction and efficiencies and provides an opportunity to leadership to move business forward.

The virtual working environment is more flexible as compared to conventional work setting. In virtual setting, synchronous and asynchronous methods are used by the team members to communicate. Team members can be monitored online with the help of camera and videos. Team leader can also use the asynchronous and synchronous methods to measure the member's performance. Asynchronous refers to electronic documents and knowledge repository whereas synchronous refers to virtual meetings and messages e.g. instant messages.

It is very obvious that leadership of virtual teams require the management and leadership skills to lead the team. In virtual setting, the members are from diverse geography, cultures and skills, it is really a challenge to coordinate and bridge the gap between such teams. It is leader's primary responsibility to build a working relationship in which team member work freely, share knowledge, expertise, feel comfortable and should make considerable contribution towards team success.

The virtual teams are not always equipped with latest technologies to perform the job. The 
virtual team members often complain about the non-availability of software for performance enhancement and they consider its leader's responsibility to provide the tools and all that for job performance. The leader considers its team members' obligation to find out the required tools for job performance. Sometime leaders restrict to use some specific tools by the team members this is not right. The leaders some established some standards tools usage by the team member but be flexible to allow to use different types tools for better performance.

Virtual team leaders are also responsible for member's emotional feelings, cohesion, norms, knowledge sharing and motivations to make members commitment towards the organizational goals. This requires the management to develop new skills in virtual leaders. So, there is a need for training of virtual leaders. There is also a need for training of members to polish their skills.

As it is a great challenge to lead the virtual team therefore the payoffs must be considerable to motivate the leaders for this way of working. As this type of teams require to access to experts in other geographical zones, therefore, the team members must be aware the norms and values of their cultures as well. The team members must be trained in such way that should be able to think globally and act locally.

It is common to understand that when organizations work in virtual environment settings there is need to modify the working environment and leadership practices. Finally, it is expected that in future the organization will prepare the leaders for virtual team's management.

\section{References}

Antonakis, J. and Atwater, L. (2002) 'Leader distance: A review and a proposed theory', The Leadership Quarterly, vol. 13, no. 6, pp. 673-704.

Avolio, B.J. (1999) Full Leadership Development: Building the Vital Forces in Organizations, Thousand Oaks: SAGE Publications.

Avolio, B.J. and Kahai, S.S. (2003) 'Adding the "E" to E-Leadership: How it May Impact Your Leadership', Organizational Dynamics, vol. 31, no. 4, pp. 325-338.

Avolio, B.J., Kahai, S.S. and Dodge, G.E. (2001) 'E-Leadership- Implications for Theory, Research and Practice', Leadership Quarterly, vol. 11, no. 4, pp. 615-668.

Avolio, B.J., Walumbwa, F.O. and Weber, T.J. (2009) 'Leadership: Current theories, research and future directions', Annual Review of Psychology, vol. 60, no. 1, pp. 421-499.

Balthazard, P., Waldman, D., Howell, J. and Atwater, L. (2004) 'Shared Leadership and Group Interaction Styles in Problem-SolvingVirtual Teams', Proceedings of the 37th Hawaii International Conference on System Sciences.

Banerjee, P. and Chau, P.Y.K. (2004) 'An evaluative framework for analysing e-government convergence capability in developing countries', Electronic Government, and International Journal, vol. 1, no. 1, pp. 2948.

Bell, B.S. and Kozlowski, S.W.J. (2002) 'A typology of virtual teams: implications for effective leadership', Group and Organization Management, vol. 27, no. 1, pp. 14-49.

Bishop, A., Riopelle, K., Gluesing, J., Danowski, J. and Eaton, T. (2010) 'Managing Global Compliance through Collaborative Innovation Networks', Procedia- Social and Behaivoural Sciences, vol. 2, no. 4, pp. 64666474.

Brake, T. (2006) 'Leading Virtual Teams', Industrial and Commercial Training, vol. 38, no. 3, pp. 116-121.

Cascio, W.F. (2000) 'Managing a Virtual Workplace', Academy of Management Executive, vol. 14, no. 3, pp. 8190.

Colfax, R.S., Santos, A.T. and Diego, J. (2009) 'Virtual leadership: A green possibility in critical times but can it really work', Journal of International Business Research, vol. 8, no. 2, pp. 133-139.

Darleen, D. (2009) 'Virtual Success : The Keys to effectiveness in leading from a distance', Leadership in Action, vol. 28, no. 6, pp. 9-11.

Gibson, C.B. and Cohen, S.G. (2006) Virtual Teams That Work Creating Conditions for Virtual Team Effectiveness, John Wiley \& Sons Inc. San Francisco. USA.

Gould, D. (1997) 'Leading Virtual Teams', Boeing Manager Magazine, May.

Greenberg, P.S., Greenberg, R.H. and Antonucci, Y.L. (2007) 'Creating and sustaining trust in virtual teams', Business Horizons, vol. 50, pp. 325-333.

Griffith, T.L., Sawyer, J.E. and Neale, M.A. (2003) 'Virtualness and Knowledge in Teams: Managing the Love Triangle of Organizations, Individuals and Information Technology', MIS Quarterly, vol. 27, no. 2, pp. 256287.

Gurr, D. (2004) 'ICT, leadership in education and e-leadership', Discourse, vol. 25, no. 1, pp. 113-124. 
Hamilton, B.A. and Scandura, T.A. (2003) 'E-mentoring: Implications for organizational learning and evelopment in a wired world', Organizational Dynamic, vol. 31 , no. 4, pp. 388-402.

Holland, J.B., Malvey, D. and Fottler, M.D. (2009) 'Health care globalization: A need for virtual leadership', The Health Care Manager (Frederick), vol. 28, no. 2, pp. 117-123.

Holton, J.A. (2001) 'Building trust and collaboration in a virtual team, Team Performance Management', $A n$ International Journal, vol. 7, no. 3/4, pp. 36-47.

Hooijberg, R., Hunt, J.G. and Dodge, G.E. (1997) 'Leadership Complexity and Development of the Leaderplex Model', Journal of Management, vol. 23, no. 3, pp. 375-408.

Howell, J.M., Neufeld, D.J. and Avolio, B.J. (2005) 'Examining the relationship of leadership and physcial distance with business unit performance', The Leadership Quarterly, vol. 16, no. 2, pp. 273-285.

Hunsaker, P.L. and Hunsaker, J.S. (2008) 'Virtual Teams: A Leaders Guide', Team Performance Management, vol. 14 , no. $1 / 2$, pp. 86-101.

Jarvenpaa, S.L. (1998) 'Communication and trust in global virtual teams', Journal of Computer Mediated Communication, vol. 3, no. 4, pp. 165-98.

Kerfoot, K.M. (2010) 'Listening to See: The Key to Virtual Leadership', Nursing Economics, vol. 28, no. 2, pp. $114-115$

Kitchen, D. and McDougall, D. (1999) 'Collaborative learning on the internet', Journal of Educational Technology Systems, vol. 27, no. 3, pp. 245-58.

Lipnack, J. and Stamps, J. (2000) Virtual Teams: People Working across Boundaries with Technology, NewYork: John Wiley \& Sons.

Luther, K. and Bruckman, A. (2010) 'Flash collabs: Collaborative innovation networks in online communities of animators', Procedia- Social and Behaivoural Sciences, vol. 2, no. 4, pp. 6571-6581.

Malhotra, A., Majchrzak, A. and Rosen, B. (2007) 'Leading virtual teams', Academy Of Management Perspective, vol. 21, pp. 60-70.

McCuiston, V.E., Wooldrige, B.R. and Pierce, C.K. (2004) 'Leading the diverse workforce', Leadership\&Organization Development, vol. 25, no. 1, pp. 73-92.

Miller, C.Z., Aqeel-Alzrooni, S. and Campbell, R.W. (2010) 'Learning to collaborate in COINs: Insights from a multidisciplinary global virtual collaboration', Procedia- Socail and Behaivoural Sciences, vol. 2, no. 4, pp. 6543-6550.

O'Connell, M.S., Doverspike, D. and Cober, A.B. (2002) 'Leadership and Semiautonomous Work Team Performance: A Field Study', Group and Organization Management, vol. 27, no. 1, pp. 50-56.

Powell, A., Piccoli, G. and Ives, B. (2004) 'Virtual Teams: A Review of Current Literature and Directions for Future Research', The Databas for Advances in Information Systems, vol. 35, no. 1.

Purvanova, R.K. and Bono, J.E. (2009) 'Transformational leadership in context: Face-to-face and virtual teams', The Leadership Quarterly, vol. 20, no. 3, pp. 343-357.

Robey, D., Koo, H.M. and Power, C. (2000) 'Situational learning in cross-functional virtual teams', Technical Communication, vol. 47, no. 1, pp. 51-66.

Rosen, B., Furst, S. and Blackburn, R. (2006) 'Training for virtual teams: An investigation of current practices and future needs', Human Resource Management, vol. 45, no. 2, pp. 229-247.

Shriberg, A. (2009) 'Effectively leading and managing a virtual team', The Business Review, Cambridge, vol. 12, no. 2, pp. 1-2.

Shulman, R.R. (2001) 'In search of e-leadership', Supermarket Business, New York, vol. 56, no. 10.

Townsend, A.M., DeMarie, S.M. and Hendrickson, A.R. (1998) 'Virtual Teams: Technology and the workplace of the future', Academy of Management Executives, vol. 12, pp. 17-27.

Townsend, A.M., DeMarie, S.M. and Hendrickson, A.R. (1998) 'Virtual Teams: Technology and the Workplace of the Future', The Academy of Management Executive, vol. 12, no. 3, pp. 17-29.

Warkentin, M., Sayeed, L. and Hightower, R. (1999) 'Virtual teams versus face-to-face teams', in Kendall Emerging Information Technologies Improving Decisions, Cooperation, and Infrastructure, K.E edition, Thousand Oaks, CA: SAGE Publications.

Watson, K.D. (2007) Remote management: Traditional leadership behaivours in a contemporary work environment, Kansas State University, Manhattan, KS.

Zaccaro, S.J. and Bader, P. (2003) 'E-Leadership and the Challenges of Leading E-Teams: Minimizing the Bad and Maximizing the Good', Organizational Dynamics, vol. 31, no. 4, pp. 377-387.

Zigurs, I. (2003) 'Leadership in Virtual Teams: Oxymoron or Opportunity?', Organizational Dynamics, vol. 31, no. 4 , pp. 339-351. 